\title{
Cosmology on the Internet: Distance Education for the Gifted and Talented
}

\author{
David H. McKinnon ${ }^{1}$ and C. J. Patrick Nolan ${ }^{2}$ \\ ${ }^{1}$ School of Teacher Education, Charles Sturt University, \\ Bathurst, NSW 2795, Australia \\ dmckinnon@csu.edu.au \\ ${ }^{2}$ Massey University College of Education, Palmerston North, New Zealand \\ P.Nolan@massey.ac.nz
}

Received 1999 October 1, accepted 2000 April 28

\begin{abstract}
In 1994, the New South Wales Board of Studies, Australia, introduced three high level Distinction Courses for gifted and talented students: Comparative Literature, Cosmology, and Philosophy. All are offered by distance education but the cosmology course employs an interactive design model and an extensive communication system that differentiates it from the other two. This paper explains the model and the way it is used in practice to organise, sequence and deliver the course. A discussion addresses ways in which the model might be used to design a wider range of courses in science for gifted and talented students.
\end{abstract}

Keywords: astronomy education—cosmology education

\section{Introduction}

In 1992, the New South Wales Board of Studies, Australia, estimated that between 2,500 and 5,000 highly gifted and talented students were enrolled in final year (Grade 12) Higher School Certificate (HSC) courses at any one time. In that year, the Board introduced reforms (NSW Board of Studies 1993) permitting such students to sit the HSC final examinations in one or more subjects earlier than Grade 12. Even then, it acknowledged that schools were not well placed to address the needs of these students. Typically, the students still enrolled in many more than the mandatory minimum number of subjects to qualify for a Higher School Certificate and a University Tertiary Entrance Rank score. Indeed, some continued to take up to twice the number of required subjects to satisfy their thirst for knowledge.

In 1993 the Board of Studies, in partnership with Charles Sturt University and the University of New England, decided to develop and deliver, using conventional distance education methods, nine high-level distinction courses. These would be especially tailored to meet the needs of gifted and talented students, providing them with the kind and level of intellectual challenge that they appear unable to get through regular school programs. The first three courses, Comparative Literature, Cosmology and Philosophy, were offered for the first time in 1994, with the expectation that the remaining six would follow soon after. This has not happened and with the reforms to the Higher School Certificate promulgated in 1998, the three existing Distinction Courses will be offered for the last time in the year 2000. It is expected that alternative arrangements will be made with all universities in NSW for gifted and talented students across the state to access first year courses either by distance education or conventionally. It remains to be seen what these alternative arrangements will be.
While all three existing courses have been delivered by distance education, the Cosmology Course is markedly different from the other two. It employs an interactive design model incorporating a comprehensive communication system ranging from conventional mail to an especially designed Internet web site. Practical experience over five years has demonstrated how the model and its delivery system may have wider application than the Cosmology Course in which they were developed and trialed. It is to be hoped that the universities will take note of the model presented in this paper as they enter into negotiations with the Board of Studies for the delivery of courses to the gifted and talented students in our high schools.

This paper explains the model and the way it has been used in practice to organise, sequence and deliver the Cosmology Distinction Course to highly gifted and talented senior secondary school students is explained. The students are widely separated from each other and the course provider, Charles Sturt University, with many living in remote places throughout the state of New South Wales. The paper is organised in sections covering: the content, structure and educational philosophy of the Cosmology Distinction Course; the interactive design model, its elements and the relationships between them; application of the model to deliver the course; and, implications and suggestions for the education of highly gifted and talented students in the future.

\section{The Cosmology Distinction Course}

Students learn and explore core concepts and ideas selected from the contemporary cosmology literature augmented by material from history, sociology and mathematics as well as physics and astronomy. Readings from two texts are supplemented by readings from such journals as Astronomy, The Astrophysical Journal, Nature, New Scientist, Scientific American and Sky \& 


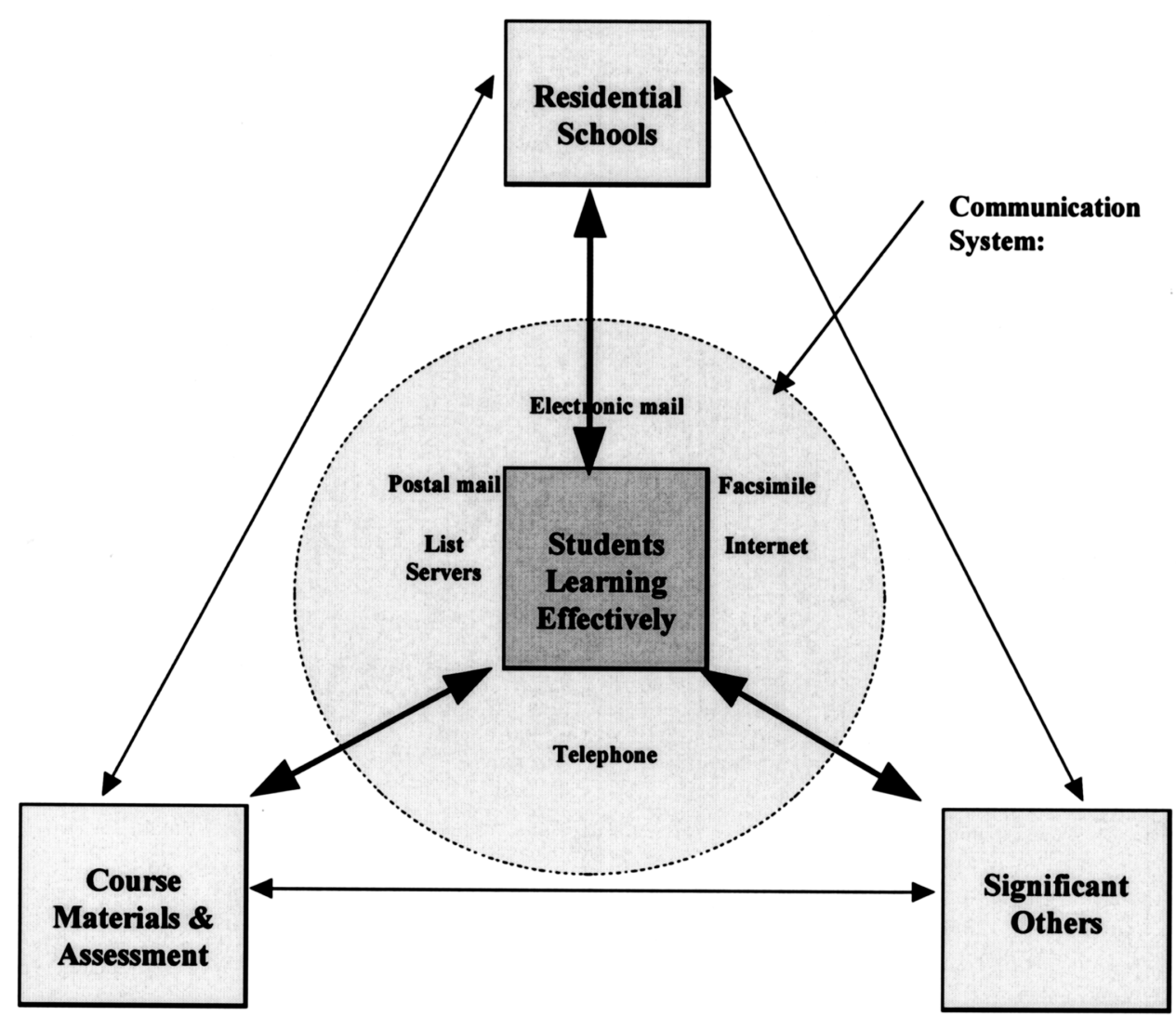

Figure 1-Model of the mixed-mode delivery system (McKinnon \& Nolan 1999).

Telescope. Each year an Update booklet is produced containing the latest research findings from the literature that relate to topics covered later in the course. These materials are distributed to students in the conventional distance education form-paper. The pile of readings in nine modules, an update booklet and an information booklet often creates concern for the students. Nonetheless, few withdraw in the early stages.

Students' learning is assessed through completion of three written assignments (30\%), two examinations $(40 \%)$ and a self-chosen major project (30\%). The project, written as a report typically between 7,000 and 12,000 words on a topic chosen by the student, is completed and submitted before formal HSC examinations begin. This approach contrasts with typical HSC procedures where $50 \%$ of the mark is based on a final examination and the other $50 \%$ on school assessment.

The primary aim of the course is to provide students with a highly challenging and motivating educational program that can be delivered to them wherever they live in New South Wales (NSW Board of Studies 1995). The educational philosophy of the course is that all scientific knowledge is contestable. In Cosmology, explanations of the universe and its origin evolve in response to the ever increasing volume of observational data that constantly challenges existing assumptions and theories. This stands in contrast with a view, common in schools, that science is an immutable body of knowledge that students must absorb and reproduce for the purposes of assessment and evaluation in the Higher School Certificate.

During the course, students experience the contestability of knowledge first hand during residential schools (an element of the design model described below) when they listen to, and interact with, leading Australian and international astronomers and cosmologists who work at the cutting edge of research. The learning and understanding begun here continues in conversations, conducted using electronic communication tools, with the astronomers and cosmologists, with peers and with the course coordinator.

Since its commencement in 1994, approximately 120 students have participated in the Cosmology Distinction Course. Almost equal numbers of female and male students have undertaken the course and they have been drawn equally from public and private sector schools in both city and country, widely distributed across the state of New South Wales. The last two years have seen a swing in favour of public sector students participating in the course (e.g. in 1999 a ratio of 20:12). Students completing the Cosmology course have subsequently enrolled in university degree courses ranging across engineering, medicine and science and some have gained entry directly to second year levels.

\section{Interactive Design Model of the Course}

The Interactive Design Model of the course is presented in Figure 1. It comprises three key design elements, 


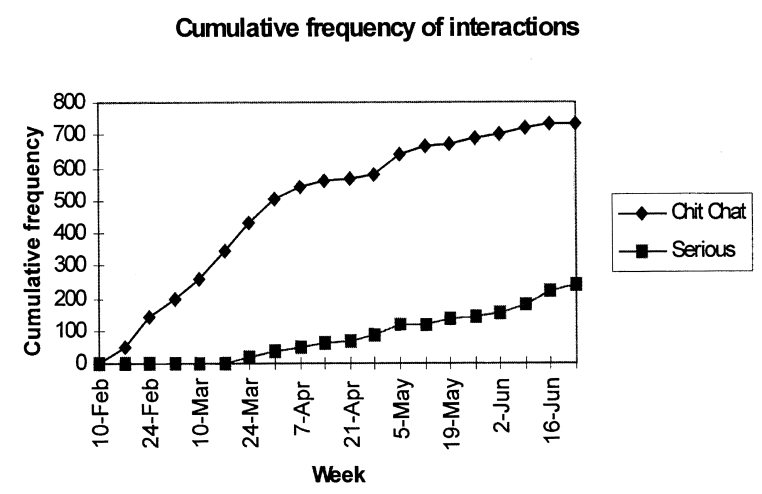

Figure 2-Cumulative frequency of interactions on the two electronic forums.

print-based study modules, residential schools and significant others, and a communication system for linking the students with the elements and with each other. The modules organise and sequence the objectives, content and assessment tasks into manageable units of study. Residential schools bring all of the students together to meet and interact with each other, engage in experiential learning at world class observatories and learn from, and interact with, leading researchers. Significant others include the course coordinator, research astronomers and cosmologists who provide students with the support and guidance they may require. During the course they interact with the students in varying capacities as facilitators of learning, mentors, critical friends, interpreters and discussants.

In the Model, the communication system connects the students in varying ways with each of the three design elements located at the vertices of the triangle. The specific means of communication range across such traditional tools as postal mail and telephone to the more modern tools of facsimile, electronic mail, list-servers and the Internet. They are the means by which the course coordinator, the students and other key persons associated with the course distribute and receive materials, interactively address and resolve issues, problems and concerns, share good ideas and communicate their latest discoveries. While in the early stage of the course, the use of postal mail, telephone and facsimile predominate, the students rapidly acquire the skills needed to make extensive use of the more sophisticated digital forms.

The location of students at the centre of the Model and also at the centre of the communication system represented by the shaded circle signifies the studentcentred nature of the course. Interaction between the design elements creates the environment for students to learn effectively throughout the course. The thin double- headed arrows signify inter-dependency among the design elements and the dynamic and mutually supportive interaction between them. The thicker arrows indicate that the students interact with each of these elements, but that the locus of control rests with them, i.e. when they are studying the course materials, participating actively in residential school activities, communicating with others, initiating, designing and completing a project, and perhaps developing new ideas.

\subsection{Interaction between Design Elements and Communication System}

The communication system in action mediates all student interactions with the three design elements of the Model. It provides them with the means to study not only the contents of the course but also to access a much wider range of research information and ideas, and significant others with whom to explore and discuss them. It does this in three main ways through use of: (i) the Internet and a web site ${ }^{*}$ especially designed for the course to access the latest research information in both astronomy and cosmology; (ii) electronic mail to communicate personally with peers, the course coordinator and significant others around the state of New South Wales and the world; and (iii) list servers to engage in debates with their peers, and others, in an open forum on topics of interest in astronomy and cosmology.

Figure 2 is a cumulative frequency chart of students' communications during 1998 on the two electronic forums (ListServe) that were set up for them. The data set for this figure are taken from interactions up to and immediately prior to the second residential school in June. In total, 32 students commenced the course in February but by April, five had decided that the workload was too great and had withdrawn. The social dimension of communicating online with their peers outnumbers the interactions related to serious cosmology topics by about 4 to 1 . Maintenance of the social relations created during the first residential school is a high priority to the students.

Rather than present extensive analyses of the interactions amongst students on the electronic forums, an attempt to capture students' increasing mastery of the communication tools as they progress through the course has been made in Figure 3. As this happens, demands made of them by the residential schools, the course content and the project necessitate both qualitative and quantitative shifts (i.e. discontinuities in the line graph) in the way they use different communication tools to engage with and master the course content. The discontinuities divide the course into four phases which correspond with changing student orientations to the course and its contents; namely, an administrative focus in Phase $\mathrm{I}$, a social interaction focus in Phase II, a content focus in Phase III, and a

\footnotetext{
* http://hsc.csu.edu.au/cosmology/. The site went live in June 1996. It supports students' research and provides them with access to additional upto-date research information on a wide range of Astronomy and Cosmology topics not contained in the individual modules.
} 


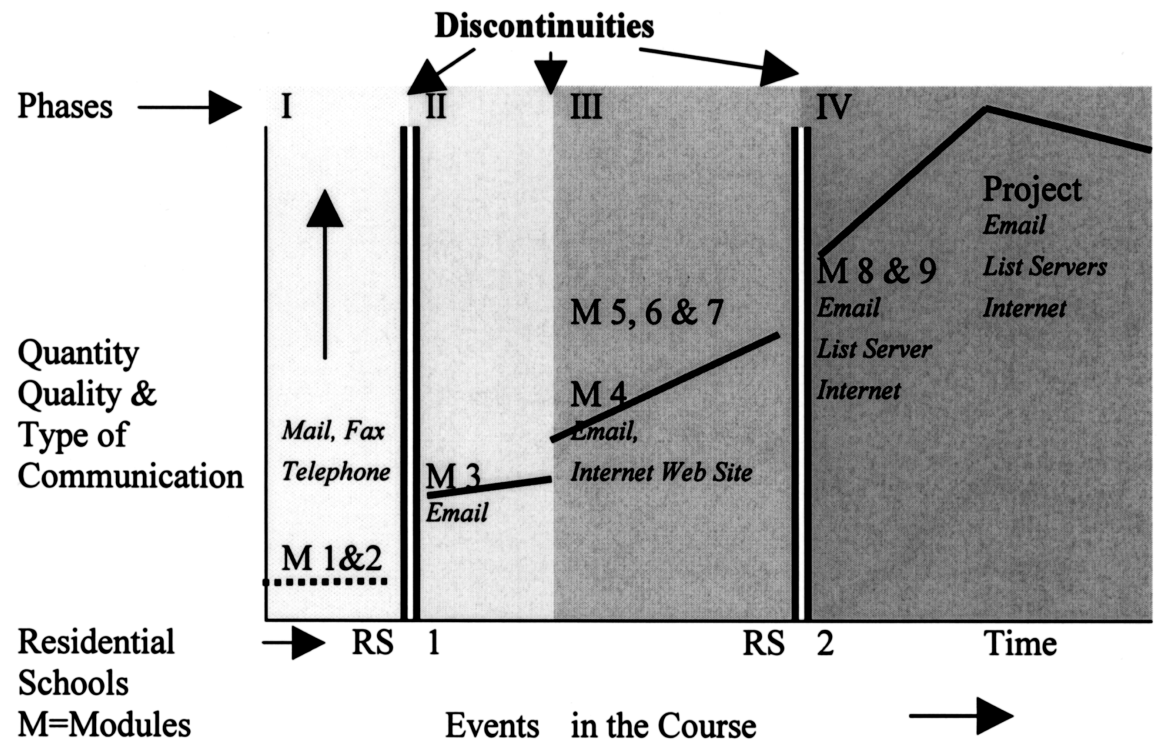

Figure 3-Quantity, quality and type of communication (McKinnon \& Nolan 1999).

focus on the project in Phase IV. Towards the end of Phase IV, students become involved with the production and presentation of their project, the final assessment item for the course. Consequently, there is less need for the same level of electronic communication. Events and activities in the first residential school and the need to conceptualise a project during the second residential school trigger the first and third discontinuities while the massive increase in intellectual demand made of students in Module 4-Space and Time-triggers the second discontinuity.

\subsection{Communication and Role of Course Modules}

During Phase I, postal mail, fax and telephone provide students with all of the course materials and answers to any questions about the organisation of the course and the first residential school. During this phase, students study Modules 1 and 2 which: (i) cover all the astronomy needed to understand the more complex cosmological concepts and models addressed in later modules, and (ii) provide basic understandings which underpin the learning experiences of the first residential school.

During Phase II, students study Module 3-The development of cosmological ideas. Their use of electronic mail, while extensive, is restricted to social interactions with their peers and the course coordinator. In this way, relationships formed at the residential school are consolidated and developed.

During Phase III, Modules 4 to 7 challenge students to broaden and deepen their understanding. They study General Relativity, the Structure of Space-Time, the Expansion of the Universe and the Use of Key Observations (e.g. the cosmic microwave background radiation) to evaluate contemporary models of our Universe. To cope with the challenge and the massive increase in intellectual demand it makes of them, they now use electronic mail (the second discontinuity) to ask key questions and raise issues and problems that they seek to resolve with the course coordinator. In response, the course coordinator sometimes communicates, or links the students, with significant others in the wider scientific community to find answers and to clarify research findings related to the questions. In addition, students learn how to use the Cosmology Internet Web Site to locate sources of information relevant to their study, or to find resources or materials pertinent to their questions and emerging interests.

During Phase IV students settle on a topic for the major project. This phase follows the second residential school during which students prepare for the project by discussing possible topics with peers, the course coordinator and visiting research astronomers. Prior to commencing the project, students complete the remaining two modules. Following the residential school, Module 8 develops students' understanding of the accepted cosmological model, the Big Bang. Importantly, Module 9 arrests any tendency to apply closure by challenging students to evaluate alternative cosmological models and ways they might be tested using new kinds of observational data. Concurrent with their study of these modules, students settle on a topic and employ all the tools of the communication system (the third discontinuity) to obtain resources and the assistance and support necessary to manage the self-directed learning and inquiry more focussed and demanding than all their previous study in this course. In this phase, students expand their expertise in using the communication system as they:

(1) use electronic mail and the Cosmology List Server to discuss and finalise project topics with their peers and the course coordinator; 
(2) use the Cosmology Web Site and the wider Internet extensively to search for, and find, material directly relevant to their project topic;

(3) employ the Cosmology List Server to exchange information about, and inform their peers of, the potentially useful Internet sites they have found;

(4) access and use other list servers to initiate conversations with, and seek information from, others who share an interest in cosmology; and

(5) use electronic mail to establish contact with some of the research astronomers they have already met, and initiate contact with others located though their use of list servers and the Internet.

\subsection{Communication and Role of Residential Schools}

The first residential school is a study tour of five major astronomical observatories in the central west and northwestern regions of New South Wales. The second is a seminar weekend held in Sydney. In both, students engage with the course content and learn about astronomy and cosmology through lectures and conversations with leading research astronomers who explain their work and its significance.

Held very early in the school year, the first begins at Siding Spring Mountain, site of two observatories and Australia's largest optical telescopes, the 3.9 metre Anglo-Australian Telescope, the 48 inch Schmidt telescope and the 2.3 metre New Technology Telescope. Extended tours enable the students to study the structure and design of each kind of telescope. They sit alongside astronomers who explain how they are using the instruments to collect data, process the data using powerful computers, and use the results to evaluate competing astronomical theories, e.g. theories about the distance scale and age of the Universe. While students are not permitted to use the main telescopes, they are allowed to use and control a 24 inch telescope during extended observation sessions to study and photograph astronomical objects of particular interest while guided by a resident professional astronomer. At the nearby 22 metre radio telescope (MOPRA), students learn how the instrument on its own can be used to examine the structure of our galaxy by studying clouds of gas and dust. They learn that the same telescope, when linked with other instruments as part of the Australia Telescope National Facility (ATNF), permits radio astronomers to observe the centres of other galaxies hundreds of millions of light years away where it is thought that black holes exist.

At Narrabri, extended tours of the Australia Telescope Compact Array and the Sydney University Stellar Interferometer enable students to understand how astronomers use these instruments to probe the detailed structure of astronomical phenomena in both the radio and visible parts of the electromagnetic spectrum. At Parkes, 300 kilometres to the south, the resident astronomer is the students' interpreter and guide. The astronomer explains how Australia's largest radio telescope can be used to collect information on many projects: for example, receiving radio signals from the Galileo probe in orbit around Jupiter; the SETI project which searches for extra-terrestrial intelligence; and, as part of the ATNF probe of the structure of our Universe, by collecting data on the spatial distribution of galaxies.

The second residential school, held mid-year, is a two day workshop when the substantive content of the course is consolidated. Four visiting astronomers run seminars on the latest developments in Cosmology. The main purpose of the residential school, however, is for the students to choose a topic for their major project that is worth $30 \%$ of their Higher School Certificate mark in the subject. The course coordinator helps students with this task, helps the students to link up with significant others upon whom they might call for help and guidance, and suggests sources of information pertinent to their topic.

In these settings, the students who are normally isolates in their own schools, meet and interact closely with their intellectual peers and the course coordinator. Through this they develop personable relationships that lead to ongoing communication through the electronic networks when they return to home and school. During the meetings, leading researchers and others model key scientific attitudes and processes such as how to obtain, and be critical of, observational data. The students learn how to exercise scepticism when presented with models and theories commonly taught as 'immutable truths' in school science.

\subsection{Communication and Role of Significant Others}

As indicated earlier, the 'significant others' of the Cosmology course are key people who can and do provide students with the support, guidance and critique they require to develop their cosmological knowledge and understanding. The course coordinator is the person of key significance for the students because of his or her overview of the course, experience in Astronomy and Cosmology, ability to provide direct and immediate support on a personal basis and ability to assist students to make contact with other key individuals. The following three vignettes illustrate the importance of the role that others play and the sense in which they become significant to the students, supporting them in their pursuit of knowledge.

Vignette 1: Why is $\boldsymbol{\pi}, \boldsymbol{\pi}$ ? In Module 4 on Space and Time, a 16 year-old male student wanted to know “... how circles 'know' that $\pi$ is the ratio between the circumference and the diameter? Is it a function of space-time? Is it just because it is?" he asked. Whereas the response of his mathematics teacher closed the discussion with a 'yes' to the third question, a series of electronic mail interactions involving the course coordinator, an astronomer and the student began to reveal to the student, and to his mentors, a far greater cosmological significance to his question. 
In response to suggestions made on electronic mail, the student calculated $\pi$ as if he were a two-dimensional being living on the surface of a sphere, e.g. the Earth. He did this for larger and larger circles drawn on the Earth's surface by calculating the ratio of circumferences to their diameters. Thus, for a circle drawn at the equator with its centre at the North Pole, the diameter is equal to half the circumference of the Earth and $\pi$ is exactly 2 ! That is, the student was able to demonstrate that $\pi$ varied between its commonly accepted value and zero, i.e. at the South Pole. He next used his finding to conduct a 'thought experiment' in which he showed that for a circle of fixed diameter, the value of $\pi$ varied depending on the size of the sphere on which it was drawn. He abstracted this finding to four-dimensional space-time and suggested how the curvature of our Universe could be measured by examining how $\pi$ varies as larger and larger circles are 'drawn' within it, i.e. circles that are significant fractions of the 'size' of the Universe. He concluded that: if the value of $\pi$ decreases the Universe is closed and unbounded; if $\pi$ remains constant then our Universe is infinite and 'flat'; if $\pi$ increases then our Universe is open and unbounded.

In this case, while the communications were frequent, sometimes lengthy and intensive over a three week period, they were conducted exclusively using electronic mail and involved only two significant others, the course coordinator and a research astronomer with a particular interest in the course.

Vignette 2: Lyman- $\alpha$ forests are not green! Material in Module 6-Further key observationsstimulated a 17 year-old male student to investigate further the ways in which observations of very distant quasars and spectral analysis of their light (the Lyman- $\alpha$ forest) can be used to understand the distribution of matter in the Universe, the relative abundance of different elements, and the constraints that this relative abundance places both on the age of the Universe and the structure of space-time. The investigation resulted in the production of a 19,000 word report rated by four university lecturers as being almost equivalent to an undergraduate honours thesis (and could have been with the inclusion of a small section which reduced actual raw data to produce a Lyman- $\alpha$ spectrum). The report was the means by which this student acquired sophisticated knowledge and understanding of complex observational techniques. In it, he demonstrated his ability to interpret the observations currently being made by researchers at the leading edge of observational astronomy.

The quality of the project was enhanced through the use of the Internet and electronic mail that the student employed over a three month period. He communicated with two research astronomers located at the University of Sydney and at NASA in the USA, neither of whom he has ever met in person. They suggested useful lines of inquiry, made helpful criticisms, supplied recent research data and research articles, and provided a great deal of encouragement.

Vignette 3: Weighing a galaxy. One 16 year-old female student joined the course because she wanted to be an observational astronomer. After an observation session conducted by the manager of the AngloAustralian Observatory during the first residential school, this student said that ' $[\mathrm{I}] \mathrm{t}$ would be really neat to do a practical project.' She was encouraged by the course coordinator and by astronomers at the residential school to pursue her desire to work on such a project and they suggested that perhaps she might join an existing research program. Over the next four months, the student made numerous inquiries by electronic mail to check on the progress being made. Enquiries made on her behalf elicited a response from the director of the Mount Stromlo and Siding Springs Observatory who arranged for her to meet, and work with, a female astronomer visiting Australia from Italy to search for 'dark matter' in spiral galaxies visible in the southern hemisphere.

Through electronic mail communication, the visiting astronomer and the student conceptualised a project that a high school student could complete involving observations to obtain spectra of spiral galaxies using the 2.3 metre New Technology Telescope. The outcome of the observations, and the collaboration that made them possible, was a project containing a detailed mathematical reduction of the observational data to produce a particular graph of the rotational velocity against the distance from the centre of one spiral galaxy. The student calculated that only about $10 \%$ of the matter in the galaxy was actually visible. The other $90 \%$, commonly referred to as 'dark matter', was at very large distances from the centre which made the galaxy behave as if it was more like a rotating sheet of card rather than a loosely bound collection of 100,000 million stars.

The project was based on a six day field trip to the Mount Stromlo and Sidings Springs Observatory where the visiting astronomer acted as a significant other in the ways described above, thereby ensuring that the student understood the mathematics required, and could carry out the relevant calculations correctly. The resulting project was awarded a high distinction by the examination committee. The experienced and neophyte astronomers remain in regular communication to this day using electronic mail from their respective homes in Australia and Italy. Now a scholarship winning university student, she is in contact with several radio and optical astronomers both personally and by electronic mail. They encourage and support her to realise her goals in astronomy.

\section{Discussion}

The achievements reported in the three vignettes are indicative of the kind of learning engaged in by the majority of students in the course. They reflect such student attributes as commitment to succeed, imagin- 
ation, creativity and intellectual virtuosity, to name a few. The nature of cosmology itself calls all the attributes into play to engage student interest. Arguably, it is the design model of the course and its delivery system that created the conditions capable of sustaining the kinds of high level inquiry that appeal to gifted and talented students. Their interest and attention is sustained over a relatively long period of time in a course they elect, rather than are required, to take. While each element of the Model contributes to the maintenance of student interest, sustained student use of the communication system appears to be the key factor.

Communication is a pervasive feature of all effective learning environments. In such environments, even the most independent learners, sooner or later, need to communicate with others. In distance education, a communication system comprising various electronic media can create learning environments very similar to classrooms where learners and teachers are in direct and immediate communication with each other, and where they can readily obtain the stimulation and support they may need. In delivering the Cosmology course, explicitly incorporating the communication system into the program design enabled students to exercise control over and manage their learning, gain the support they required and achieve results that were personally satisfying.

Students report that the communications aspect is what really makes the difference for them between a normal HSC course and the quality of the learning they experience in the Cosmology Distinction Course. Key factors and elements include: (i) the personal contact and communication with individuals in Australia and around the world who are committed and passionate about cosmology and learning in general; (ii) the ability to meet and interact with peers who they otherwise might not ever get to know; and (iii) the validation of best ideas, discoveries and intuitions from others who actually understand what a student may be thinking and wanting to do, and who take both seriously.

In the form of distance education based on the Model, the concept of 'learning community' largely replaces the concept of 'teacher'. In the learning community of the Cosmology course, with the participants connected electronically, the students play roles principally as learners while significant others, e.g. the course coordinator and astronomers, play the roles referred to earlier in the paper as facilitators of learning, mentors, critical friends, interpreters and discussants.

The provision of an Internet web site devoted to supporting the students' own research in Cosmology continues to develop. New sites appear almost on a weekly basis. Students now post their findings of important and relevant web sites to the Cosmology site for others to peruse. While the final projects presented in previous years were of a generally high quality, the projects produced through use of the Internet stand out as excellent. The Internet provided these students with resources that kept them up to date with the latest developments. New discoveries arising from the developments are exciting and the excitement is infectious. Access to the Internet and the Cosmology Web Site communicated this excitement and helped the students to maintain high levels of interest and motivation.

If use of the interactive design model created an environment conducive to high level learning and achievement in the Cosmology Course then there appears to be no reason why, in principle, it cannot be applied more widely to develop and deliver other courses and programs for gifted and talented students. In the present case, the students happened to be working at the HSC level. Meeting the needs of these students may deserve priority at a point when they are on the verge of university study. It is equally important to consider ways the Model might be used to develop courses suitable for both a wider and younger range of gifted and talented students.

It is important to note, in passing, that changed political circumstances and recommendations made in a recent review of the Higher School Certificate (McGaw 1997) will result in the discontinuation of Distinction Courses per se and the other six courses referred to at the outset will not now be developed. The Government will initiate, however, joint discussions involving the Board of Studies, school education authorities and universities to negotiate curriculum, delivery, and credit transfer arrangements, and in the meantime retain the existing courses until the proposed new arrangements with universities are established (NSW Government 1997). It is now planned that Distinction Course will end in the year 2000. Negotiations with universities are slow to start. Little time remains if they are to offer access under the new Higher School Certificate umbrella in the year 2001 .

The curriculum at this level needs to be negotiated to the benefit of our brightest students so that their potential can be developed and that they are not disadvantaged. The underlying message is that schools and universities must increasingly consider ways by which communication and information technologies might be employed either to enhance, and perhaps replace, existing delivery methods in the interests of continually improving secondary school education for the gifted and talented, and in time perhaps even the broad range of students. To the extent that the Interactive Design Model has demonstrated its value, then it suggests a strategy for delivering high quality education by the schools of the future.

\section{References}

McGaw, B. 1997, Shaping their future: Recommendations for reform of the Higher School Certificate. Department of Training and Education Coordination, New South Wales

McKinnon, D. H., \& Nolan, C. J. P. 1999, Distance education for the gifted and talented: An interactive design model. The Roeper Review, 21, 320-5 
NSW Board of Studies 1993, HSC Pathways Implementation Guidelines (North Sydney: Board of Studies NSW)

NSW Board of Studies 1995, Higher School Certificate Distinction Courses: An information book (North Sydney: Board of Studies NSW)
NSW Government 1997, Securing their future: The NSW Government's reforms to the Higher School Certificate (Sydney: NSW Government Printer) 